\title{
BMJ Open Use of environmental scans in health services delivery research: a scoping review
}

\author{
Patricia Charlton (D) , ${ }^{1}$ Terri Kean (D) , ${ }^{2}$ Rebecca H Liu (D) , , Daniel A Nagel (D) , \\ Rima Azar, ${ }^{5}$ Shelley Doucet (D) , ${ }^{6}$ Alison Luke (D) , ${ }^{6}$ William Montelpare (D) , \\ Kim Mears, ${ }^{8}$ Leah Boulos ${ }^{9}$
}

To cite: Charlton $\mathrm{P}$, Kean $\mathrm{T}$, Liu RH, et al. Use of environmental scans in health services delivery research: a scoping review. BMJ Open 2021;11:e050284. doi:10.1136/ bmjopen-2021-050284

- Prepublication history and additional supplemental material for this paper are available online. To view these files, please visit the journal online (http://dx.doi.org/10.1136/ bmjopen-2021-050284).

Received 15 February 2021 Accepted 13 August 2021
Check for updates

(c) Author(s) (or their employer(s)) 2021. Re-use permitted under CC BY-NC. No commercial re-use. See rights and permissions. Published by BMJ.

For numbered affiliations see end of article.

Correspondence to Dr Patricia Charlton; pcharlton@upei.ca

\section{ABSTRACT}

Objective To examine the extent and nature of evidence on the use of the environmental scan (ES) in the health services delivery literature.

Design Scoping review.

Methods This scoping review followed the five-stage scoping review methodology outlined by Khalil et al. A Peer Review of Electronic Search Strategies was completed. Seven electronic databases and the grey literature were searched. Pairs of researchers independently performed two levels of screening and data extraction. Data were analysed using qualitative content and thematic analysis. Results Ninety-six studies were included in the scoping review. Researchers conducted ESs for many purposes, the most common being to examine the current state of programmes, services or policies. Recommendations were informed by ESs in $20 \%$ of studies. Most common data collection methods were literature review $(71 \%)$, key informant or semistructured interviews (46\%) and surveys $(35 \%)$. Over half $(53 \%)$ of the studies used a combination of passive (looking at information eg, literature, policies, guidelines) and active (looking for information eg, surveys, interviews) approaches to data collection. Person sources of data (eg, healthcare stakeholders, community representatives) and non-person sources of data (eg, documents, electronic databases, the web) were drawn on to a similar extent. The thematic analysis of the definitions/ descriptions yielded several themes including instrument of discovery, knowledge synthesis, forward-looking and decision making. Research gaps identified included absence of a standard definition, inconsistencies in terminology and lack of guiding frameworks in the health services delivery context.

Conclusion ESs were conducted to gather evidence and to help inform decision making on a range of policy and health services delivery issues across the continuum of care. Consistency in terminology, a consensus definition and more guidance on ES design may help provide structure for researchers and other stakeholders, and ultimately advance ES as a methodological approach. A working definition of ES in a health services delivery context is presented.

\section{INTRODUCTION}

Environmental scanning, a process designed to gather information to inform and direct

\section{STRENGTHS AND LIMITATIONS OF THIS STUDY}

$\Rightarrow$ This scoping review addresses an important knowledge gap - the use of environmental scans in the health services delivery literature-and includes a comprehensive analysis of the peer-reviewed and grey literature.

$\Rightarrow$ The study followed established and systematic methods for conducting scoping reviews.

$\Rightarrow$ For the grey literature search, limits were placed on the number of platforms searched and articles selected per platform. Some relevant studies may have been missed; however, our comprehensive search strategy helped mitigate this limitation.

$\Rightarrow$ Only English-language studies were considered for this scoping review.

$\Rightarrow$ The included studies were not assessed for methodological quality.

organisational change, is deeply rooted in the business sector. ${ }^{1}$ Leaders in other sectors over the past several decades have come to understand the need to acquire, organise, evaluate and mobilise different kinds of knowledge to inform decision-making processes, anticipate and interpret trends, adapt organisational behaviour, energise organisational growth, mitigate institutional risk and develop strategies in response to rapidly changing environments. ${ }^{2-8}$

\section{Scanning characteristics}

Environmental scanning can range from formal to informal activity and is influenced by individual, contextual and organisational factors. ${ }^{19-13}$ Formal scanning is systematic, continuous, proactive, prospective and coordinated, and is undertaken to inform decision making on circulating trends, threats or issues. ${ }^{1514}{ }^{15}$ Environmental scanning may also be conducted on a less formal, irregular and reactive basis often triggered by a crisis or specific issue. ${ }^{11}{ }^{14-17}$ Regardless of 
the approach, environmental scanning is viewed as an important means of organisational learning. ${ }^{12}$

Environmental scanning is integral to strategic planning and involves an analysis of an organisation's external and internal environments. ${ }^{213}{ }^{18-21}$ The external environment includes elements outside the boundaries of an organisation (eg, political/legal, technological, sociocultural environments, customers, suppliers, strategic partners, etc). ${ }^{1922} 23$ The internal environment may include elements of an organisation, for example, structure, budget, workforce capacity and/or leadership). ${ }^{23-27}$

Information is drawn from person sources (eg, staff, community, experts) and/or non-person sources (eg, databases, documents, the Web). ${ }^{5628} 29$ Person and nonperson sources may be internal (accessible within the boundaries of an organisation) or external (accessible beyond the boundaries of an organisation). ${ }^{4528}$ The selection of data sources may be influenced by accessibility to information, quality of information and environmental uncertainty (constant change within an environment). ${ }^{1011243031}$

\section{Environmental scans and health services delivery}

While environmental scanning is conducted by healthcare organisations as part of strategic planning, ${ }^{32-36}$ an environmental scan (ES) is frequently reported in health literature as a methodological approach to examine a specific health issue. For example, ESs have been used to: explore patient safety education and healthcare provider training programmes; ${ }^{37}{ }^{38}$ create quality indicators for health services (eg, fall prevention and adult critical care) $3^{3940}$ inform the design of cancer prevention programmes $^{29} 41$ and; explore the availability of health information resources. ${ }^{42}$ Several studies have noted the utility of ESs for assessing community needs and for programme and policy development. ${ }^{28} 294143$

Despite the potential of ESs to inform policy and practice, consensus on a working definition does not appear to exist ${ }^{29} 4144$ and practical guidance to design and/or implement ESs is lacking in the literature. ${ }^{41}{ }^{45}$ Guiding frameworks or models exist in the business and other sectors, ${ }^{25141646-48}$ yet few have been developed specifically in a health services delivery context.$^{28} 2941444$ To build on previous research and address the knowledge gaps noted above, this scoping review provides a synthesis of evidence about the nature and extent of the use of ESs in the health services delivery literature. To our knowledge, this is the first scoping review on this topic. Research and evaluation of ESs may enhance the approach to ES and its utility to support decision making in health policy and practice. $^{294144}$

\section{METHODS}

This scoping review followed the five-stage methodology outlined by Khalil et al that builds on previous scoping review methodologies of Arksey and O'Malley, Levac et al, and the Joanna Briggs Institute. ${ }^{4-55}$ The
Preferred Reporting Items for Systematic Reviews and Meta-Analyses (PRISMA) Extension for Scoping Reviews reporting guidelines were followed. ${ }^{5156}$ The steps for the review are briefly presented here; however, a full description of the scoping review protocol can be found in Charlton et al. ${ }^{45}$

\section{Identifying the research questions}

The research questions for this scoping review were:

1. How have ESs been conceptualised and operationalised by stakeholders in the health services delivery literature? (eg, characteristics including existing definitions, ES purpose, healthcare issues, settings, design, methods, data sources, scanning modes).

2. What limitations, if any, were described in the included studies that use ESs in the context of health services delivery?

\section{Identifying relevant studies}

A three-step search strategy was developed by an experienced librarian (LB) with the research team and peerreviewed (KM) based on the Peer Review of Electronic Search Strategies guidelines. ${ }^{57}{ }^{58}$ Seven electronic databases were searched: CINAHL, MEDLINE, PsycINFO, ERIC, Embase, Canadian Business \& Current Affairs, and Academic Search Premier (see online supplemental file 1 for an example of the search strategy for Medline).

Relevant grey literature was identified through searches of the New York Academy of Medicine Library Online Catalog $^{59}$ and Grey Matters, a resource developed by the Canadian Agency for Drugs and Technologies in Health $(\mathrm{CADTH})^{60}$ for searching health-related grey literature, using the search term "environmental scan". Google and Google Scholar searches were also conducted using the search terms "environmental scan" and health services, and intitle: ("environmental scan" and health) filetype:pdf-professional development-performance -college-university. To balance comprehensiveness with feasibility, the searches of Google, Google Scholar and the NYAM, were limited to the first 10 pages (or first 100 hits). For CADTH's Grey Matters, the top 10 websites/ databases deemed most relevant to the objectives of the study were selected to identify studies. Some relevant studies may have been missed, however, our comprehensive search strategy helped mitigate this limitation. The reference lists of peer-reviewed sources were also hand searched for relevant studies.

\section{Selecting studies}

Articles considered for inclusion were specific to health services delivery, published in English and reported on the use of an 'ES' as a methodological approach. No limitations were placed on publication date, population, health service, healthcare setting (eg, primary care, acute care), healthcare discipline or geographical location.

Two reviewers independently screened titles and abstracts (PC and KK) and full-text articles of the peerreviewed literature (PC and $\mathrm{TK}$ ) to assess for study 


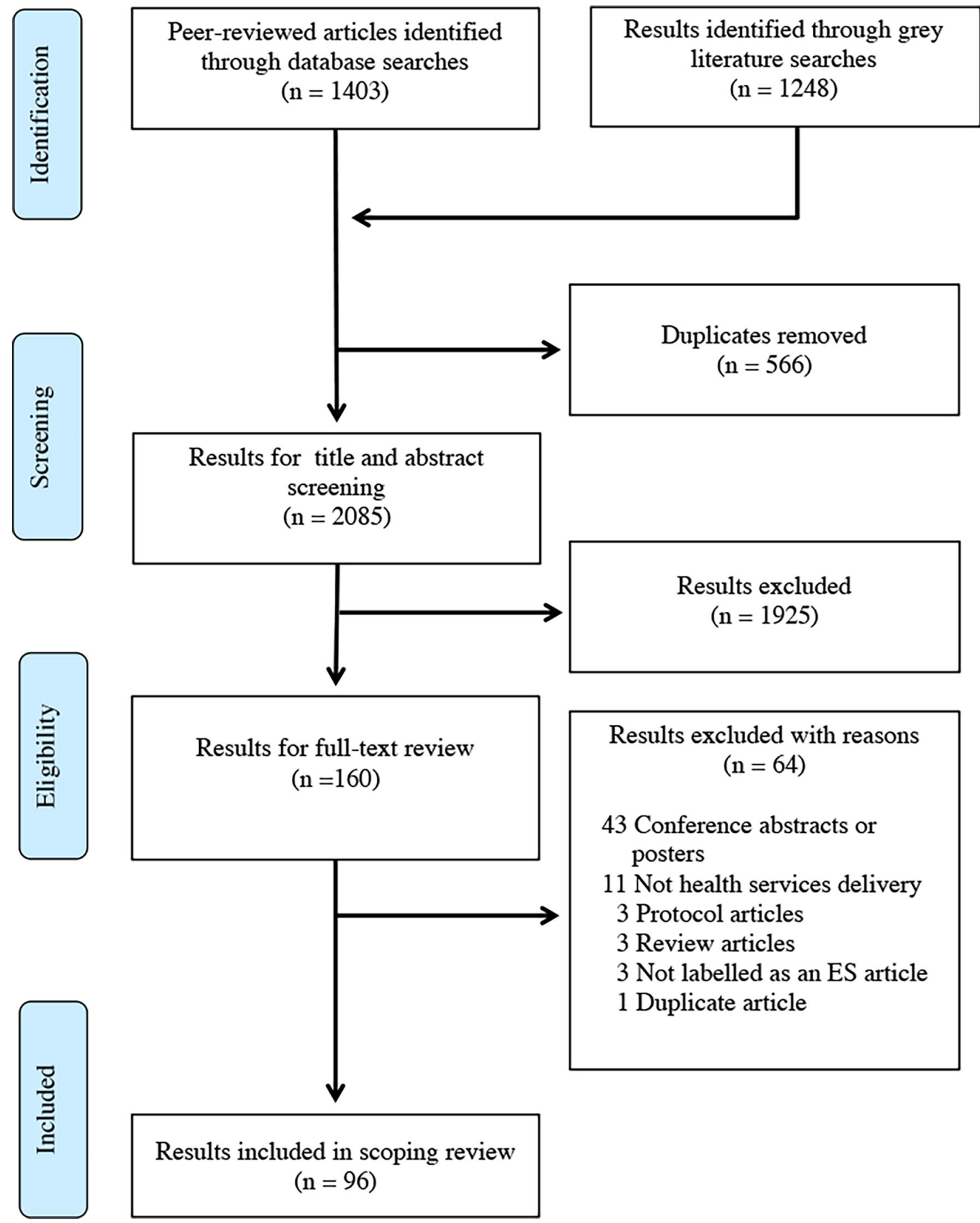

Figure 1 PRISMA flowchart. PRISMA, Preferred Reporting Items for Systematic Reviews and Meta-Analyses.

eligibility. Pilot tests were conducted at the beginning of first level (titles and abstracts) and second level (fulltext) screening to evaluate reviewer agreement and to ensure consistency. Similarly, for the grey literature, six team members worked in pairs to conduct both levels of screening (RHL, DAN, AL, TK, RA and PC). Disagreements on study selection in the screening process were resolved through discussion or, if necessary, by a third reviewer (PC, TK and WM). A modified version of the PRISMA flow chart for this review is found in figure $1 .{ }^{5661}$

\section{Charting the data}

The team developed a standardised data extraction form to chart the data. Extracted data elements included author, country, publication year, publication type, purpose of the study, purpose of ES, health condition, health domain, setting, design, methods, data sources, data source mode, scanning mode, as well as other relevant information including existing definitions, guiding frameworks and limitations.

Working definitions for the extracted data elements were developed to provide clarity and consistency among 
researchers during the data extraction process. For instance, scanning mode was recorded following two of the four levels of scanning described in the Choo model ${ }^{1}$ - conditioned viewing and searching. In this model, viewing information (ie, 'looking at' information), is considered 'passive' data collection, while searching (ie, 'looking for' information) is considered 'active' data collection. ${ }^{1}$ Similar to Naumann $e t$ $a l l^{44}$ we categorised scanning mode into two of the four scanning modes described by $\mathrm{Choo}^{1}$ as these were deemed most relevant to this review. The term scanning mode has also been used to describe data sources (ie, internal/external and personal/impersonal) in some studies. ${ }^{31}$ Therefore, for clarity the term data source mode was chosen to refer to the environment from where the data source emerged (ie, internal or external source) and the nature of the data source (ie, person/non-person).

Four teams of paired reviewers (PC, TK, PC, RA, TK, AL, RHL, DAN) independently extracted data from the peerreviewed and grey literature. Pilot tests of data extraction were conducted to assess agreement and promote consistency between reviewers. ${ }^{5262}$ The team identified initial categories for the data elements and additional relevant categories and sub-levels of categories were added as we became more familiar with the literature. Each pair of reviewers met regularly to review extraction results and to resolve any discrepancies through discussion.

\section{Collating results}

Content and thematic analysis were used to analyse the extracted data ${ }^{63}{ }^{64}$ Content analysis was conducted using SAS Edition V.3.6 and included a descriptive analysis using frequency counts and percentages to describe study characteristics. A manual thematic analysis was conducted to detect possible themes within the definitions of the reviewed studies. Data familiarisation was achieved by reading and rereading the included articles and the extracted definitionrelated data. Preliminary ideas were recorded and coded to reflect potential contribution to a theme. The initial themes were reviewed and refined until the final themes were determined.

Team members (PC, TK, RHI, DAN, RA, SD, AL, WM) reviewed and discussed the preliminary findings. The data are presented in tabular form which includes a narrative and descriptive numerical summary of the studies' characteristics (online supplemental files 2-5), ES definitions and descriptions (online supplemental file 6) and thematic analysis details (online supplemental file 7). Knowledge gaps and implications for policy, practice and research are highlighted.

\section{Patient or public involvement}

No patients or public were involved in the design or implementation of the scoping review.

\section{RESULTS}

Ninety-six studies were included in this scoping review: 60 from peer-reviewed literature ${ }^{29} 4465-122$ and 36 from grey literature. ${ }^{123-158}$ Findings suggest ESs were conducted for a wide range of purposes, defined in various ways and employed a variety of methods. Few studies were guided by a methodological framework for conducting an ES. A summary of study characteristics is presented here (see online supplemental files 2-5 for further detail).

\section{General characteristics}

\section{Publication date and country of origin}

Studies originated from three countries including Canada (68\%), USA (28\%) and Australia (4\%) with publication dates from 2001 to 2019 inclusive. Among the 96 studies reviewed, the rates of published studies that used ESs in a health services delivery context increased from about $6 \%$ (2001-2006) to 20\% (2008-2011) to $30 \%$ (2012-2015) and to $44 \%$ (2016-2019).

\section{Population, healthcare setting and health conditions}

Populations under inquiry ranged from newborn to older adult and the healthcare setting spanned the continuum of healthcare services. Most studies (57\%) were situated in multiple settings followed by primary care or primary healthcare $(13 \%)$, acute care $(7 \%)$, and regional cancer centres/facilities $(6 \%)$. Several health settings appeared in $4 \%$ or less of the studies, for example, ambulatory care, rehabilitation, palliative care/end-of-life, Veterans Affairs and community emergency response services. Of the 96 studies reviewed, $55 \%$ focused on chronic disease, $8 \%$ on infections or infectious disease and $8 \%$ other conditions (eg, end-of-life, injury); $31 \%$ did not focus on a particular health condition.

\section{Purpose of the ESs}

The reported purposes of the ESs varied across studies (see table 1). The two most reported purposes were to (1) examine the current state of programmes, services or policies $(82 \%)$ and (2) identify patient/community /organisation needs, strengths, challenges, barriers and service gaps $(58 \%)$.

In $20 \%$ of the studies, the ES and other methods informed policy and/or practice recommendations. For example, the ES helped to inform recommendations to: improve HPV vaccination rates; ${ }^{68}$ evaluate technologyassisted patient access to clinical information; ${ }^{88}$ promote perinatal mental health and support among immigrant women; ${ }^{104}$ develop institution-specific policies and procedures on the use of continuous infusion pumps during radiation treatment; ${ }^{69}$ develop a model of care for osteoarthritis management; ${ }^{150}$ and develop standards of care for cancer diagnostic assessment programmes. ${ }^{74}$

\section{Data collection approach and methods used in the ES}

A variety of data collection methods were used and about $64 \%$ of the studies used more than one data collection method. Within the ES component of the studies, the most common data collection methods were literature review (ie, peer-reviewed and grey literature) (71\%), followed by key informant or semi-structured interviews $(46 \%)$, surveys $(35 \%)$, other types of person contact (eg, emails, advisory groups, networks, expert panels), (28\%), 
Table 1 Reported purpose(s) of the ES within reviewed studies

\begin{tabular}{|c|c|}
\hline Purpose of the ES(s) & Studies \% (n) \\
\hline $\begin{array}{l}\text { Examine the current state of programmes, } \\
\text { services or policies }\end{array}$ & $82(79)$ \\
\hline $\begin{array}{l}\text { Identify and/or assess patient/community/ } \\
\text { organisation needs, strengths, challenges, } \\
\text { barriers and service gaps }\end{array}$ & $58(56)$ \\
\hline $\begin{array}{l}\text { Identify and/or assess tools for patient } \\
\text { care, or inform development of tools/ } \\
\text { education materials/patient decision aids }\end{array}$ & $23(22)$ \\
\hline $\begin{array}{l}\text { Understand the use or experience of a } \\
\text { phenomenon or service }\end{array}$ & $22(21)$ \\
\hline $\begin{array}{l}\text { Inform programme planning, design and/or } \\
\text { improvement }\end{array}$ & $20(19)$ \\
\hline $\begin{array}{l}\text { Inform recommendations for policy and } \\
\text { practice }\end{array}$ & $20(19)$ \\
\hline $\begin{array}{l}\text { Identify best practices or innovative } \\
\text { practices }\end{array}$ & $15(14)$ \\
\hline $\begin{array}{l}\text { Inform/guide quality improvement and/or } \\
\text { patient safety initiatives }\end{array}$ & $14(13)$ \\
\hline $\begin{array}{l}\text { Inform aspects of practice or policy } \\
\text { development or change }\end{array}$ & $10(10)$ \\
\hline Assess or inform models of care & $10(10)$ \\
\hline $\begin{array}{l}\text { Assess or inform clinical practice } \\
\text { guidelines }\end{array}$ & $9(9)$ \\
\hline $\begin{array}{l}\text { Inform the development of planning or } \\
\text { evaluation frameworks }\end{array}$ & $8(8)$ \\
\hline $\begin{array}{l}\text { Inform improvements in the transition of } \\
\text { care }\end{array}$ & $6(6)$ \\
\hline $\begin{array}{l}\text { Inform future research or research } \\
\text { programme }\end{array}$ & $6(6)$ \\
\hline $\begin{array}{l}\text { Inform standardisation of services, } \\
\text { processes, structure/organisation and } \\
\text { delivery }\end{array}$ & $3(3)$ \\
\hline $\begin{array}{l}\text { Understand factors influencing health } \\
\text { behaviours }\end{array}$ & $2(2)$ \\
\hline $\begin{array}{l}\text { Assess or inform other types of guidelines } \\
\text { and standards such as for use of } \\
\text { technology }\end{array}$ & $1(1)$ \\
\hline
\end{tabular}

Percentages do not add to 100 because there may be more than one purpose for an environmental scan.

$\mathrm{ES}$, environmental scan.

other methods (eg, mapping exercise, site visits) (17\%), and focus groups $(3 \%)$.

\section{Scanning mode and sources}

About $23 \%$ of the studies relied solely on active data collection methods while $22 \%$ used only passive data collection methods. Over half (53\%) reported using a combination of passive and active data collection methods for the ES component of the study.

Over half $(53 \%)$ of the studies used a combination of person and non-person data sources, $23 \%$ used only person data sources and $22 \%$ used only non-person data sources. Non-person data sources included: the Web $(58 \%)$ (eg, accessing reports, guidelines, policy documents, tools, resources), academic databases (38\%), other reports, documents, grey literature accessed through contacts $(26 \%)$, administrative databases $(4 \%)$ and other sources (eg, social media) (11\%).

Data source modes were classified into one of four categories: internal person sources, internal nonperson sources, external person sources and external non-person sources. Overall, about $70 \%$ of the studies included external non-person sources, 65\% external person sources, 31\% internal person sources and $19 \%$ internal non-person sources. Eight per cent of these studies included all four data source modes.

\section{Conceptual characteristics}

ES definition and description

Less than one-quarter $(22 \%)$ of the studies provided a definition and/or a description of ES. Within the 21 studies that provided this information (18 peer-reviewed and 3 grey literature), $12(57 \%)$ studies cited the work of Graham et $a l,{ }^{28} 6$ studies (29\%) referenced or cited the definition by $\mathrm{Choo}^{2}$ and 7 studies (33\%) cited the work of Rowel et al, ${ }^{29}$ Graham et $a l^{28}$ and Rowel et $a l^{29}$ also cited $\mathrm{Choo}^{2}$ as influential. (see online supplemental file 6$)$.

The thematic analysis of definition/description-related data of the 21 studies yielded several key themes: instrument of discovery, forward-looking, knowledge synthesis and decision making (see codes and themes in online supplemental file 7 ). Most of the 21 studies $(81 \%)$ classified ES as a distinct entity or mechanism (eg, 'a tool', 'a review', 'a method') while others described the action or process of environmental scanning. 6599110114 Nearly three-quarters $(71 \%)$ of these studies used language (eg, 'raise awareness of issues', 'develop insight', 'to identify emerging issues') that suggested the acquisition of new knowledge was a function of an ES. Most of the studies $(71 \%)$ used ES descriptors that were future oriented (eg, 'may inform future planning', 'to enable strategic action', 'opportunities for improvement'). About half (48\%) of the studies conveyed the importance of an ES in synthesising information (eg, "the identification and synthesis of evidence', 'publicly available information is gathered systematically and is used to evaluate', 'to identify and collate a large body of information'). Many studies (43\%) used terms within the definition/description-related data that suggested an ES could guide and support decision making (eg, 'assist in health decision making', 'to facilitate with strategic planning and decision making', 'analyse information to guide the direction'). Finally, some definitions/descriptions made reference to scanning the external environment citing the work of Choo, ${ }^{29} 101$ while others included reference to both the internal and external environments ${ }^{65114}$ or to internal and external data sources. 44687393 


\section{ES terminology}

Terms to describe an ES varied across the literature. The most common term used was 'tool'

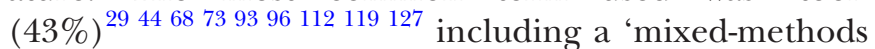
tool" 73 and a 'needs assessment tool'. ${ }^{119}$ Other terms used to describe an ES were 'an objective review', 'review' or 'rapid review'; 158 'method' or 'research method'; 65114 'research approach', 110 'cross-sectional survey' ${ }^{84}$ and 'integral process'. ${ }^{153}$ Environmental scanning was further described as systematic, ${ }^{29} 114$ and ESs as a flexible ${ }^{73}$ and economical $^{73}$ approach for collecting information.

\section{Guiding frameworks or models for ES}

Of the 96 studies reviewed, $18 \%$ were conducted by the Canadian Agency for Drugs and Technologies in Health (CADTH) researchers using organisationspecific processes for conducting ESs. Of the remaining 79 studies, 5 studies $(6 \%)$ reported being informed or guided by a specific ES model or framework (4 peerreviewed articles ${ }^{29448299}$ and 1 grey literature article. ${ }^{127}$ ) Of these five studies, two ${ }^{29} 99$ were guided or informed by Choo's conceptual model, ${ }^{2}$ one ${ }^{44}$ was guided by Choo ${ }^{2}$ and the American Society of Association Executives frameworks, ${ }^{159}$ and one ${ }^{127}$ was guided by the Wilburn et al model which was specific to the public health context. ${ }^{41}$ The fifth study implemented a 'built' ES which assesses the environmental factors that influence an organisation (eg, programmes, policies and physical features) using a school-based evaluation model. ${ }^{82}$ In addition, two studies ${ }^{123} 153$ reported being guided by scoping review methods. Several other studies in this scoping review included conceptual models that were not specific to ES but were used to guide analysis and reporting of results. 75107110127134142153157158

\section{Methodological and other observations}

In most studies, the ES was the primary methodological approach. In other studies, the ES represented one of multiple methodological approaches used within a study. 69 72 86-88 90103115127131132155158 For example, in some studies ESs were conducted in combination with a systematic review $^{74108131132155}$ or a scoping review. ${ }^{44107127}$ Several studies reported that the findings of the ES component of the study was used to validate information gathered from other methods used in those same studies such as a scoping review, interviews, focus groups or surveys. ${ }^{4483} 86$

Finally, several studies emphasised the importance of engaging stakeholders in the ES process. ${ }^{2968153}$ For example, Baezconde-Garbani et a ${ }^{68}$ noted the central role of engaging stakeholders in developing plans to increase HPV vaccination rates.

\section{Limitations of the reviewed studies}

A discussion of study limitations was included in about $65 \%$ of the studies. The most common limitations were those related to the search strategy, sampling, design, data collection methods and response rate. Overall, similar limitations were noted across peer-reviewed and grey literature.

\section{DISCUSSION}

This scoping review provides insight into how ES are conceptualised, designed and operationalised in the health services delivery literature, a topic that had not been extensively examined or well understood. ESs were conducted to gather evidence and to help inform decision making on complex policy and health service delivery issues in a range of settings across the continuum of healthcare services. However, significant conceptual and methodological gaps were also identified.

First, the findings of this review underscore inconsistencies in the terminology used to describe and define ESs in a health services delivery context. Terminology to define the ES as an entity varied (eg, a needs assessment tool, method, review, process), and where a definition or description was provided, the content and emphasis also varied. Despite lack of clarity of terminology and/or definition, research using ES has continued. Data from this review indicate the number of published ESs in health services delivery has increased from 6\% (2001-2006) to $44 \%$ (2016-2019).

It is not unusual to find inconsistencies in terminology ${ }^{160-162}$ and/or definitions ${ }^{161}$ in widely used concepts and methodologies. Consistency in terminology and/or definition can improve reader understanding and experience, ${ }^{160} 162$ increase confidence and efficiency of researchers in implementing high-quality studies, ${ }^{161} 162$ and improve knowledge translation. ${ }^{161}$ The provision and use of clear and consistent ES-related terminology and/ or definition may limit uncertainty among researchers when deciding whether to choose an ES for a research study, advance the ES as a methodological approach, ${ }^{29}$ and potentially enhance the strength of ESs to support decision making on policy and practice.

Among the studies that included an ES definition and/or description, the works of three researchers were most cited, ${ }^{2} 2829$ including the Choo model ${ }^{2}$ which built on previous frameworks ${ }^{163} 164$ and was developed in the business sector. Notably, these works were all published over a decade ago, signalling an opportunity for new research and further work to explore development of a consensus on a formal definition of ES in the context of health services delivery. This conceptual gap was noted by (Rowel, p533 ${ }^{29}$ ) who stated 'The lack of clear definition or methodology for ES could weaken its efficacy for public health practice if it were confused with other research tools or processes, such as a comprehensive needs assessment'.

Given this conceptual gap, and based on the analysis of the 96 studies in this scoping review, discussions with our research team, and previous research and definitions, ${ }^{2} 2829414484114153165$ a working definition of ES was developed as a preliminary step towards the potential development of a formal definition of ES within the 
Box 1 Working definition of an environmental scan (ES) in the health services delivery context

Within a health services delivery context, an ES is a type of inquiry that involves the collection and synthesis of existing information and/or the pursuit of new evidence to inform decision-making and help shape future response(s) to existing and emerging policy and service delivery issues and opportunities.

Drawing information from any source within the internal and/or external environments of an organisation, an ES is often conducted to: examine the current landscape of services, practices, and/or policies; identify needs, service barriers, gaps and priorities; inform planning, policy, and programme design; inform quality improvement and patient safety initiatives; and identify successful strategies, models and innovations to inform system transformation.

context of health services delivery (box 1). The characteristics of the ESs identified in this scoping review and the four key themes identified through the thematic analysis (instrument of discovery, forward-looking, knowledge synthesis and decision making) underpin the working definition. This definition is distinct to health service delivery because it provides specifics about the nature of the information, how it is gathered, and the environments from which information is gathered. It also states the purpose of ESs.

Second, our findings indicate a notable lack of formal guidance to support healthcare stakeholders in their attempts to design and conduct ESs within a health services delivery context. These methodological gaps were noted in several of the studies included in this review ${ }^{29} 44112127$ as well as in other literature. ${ }^{41}{ }^{43}$ Studies noted the lack of specific methodology or guidelines for conducting ESs. ${ }^{43} 44112127$ Inconsistencies in methodology were also noted when designing this scoping review. In several existing studies about environmental scanning, researchers referred to data source as 'scanning mode, 101231 while others referred to scanning mode as a component of a conceptual model. ${ }^{2} 163166$

Among the studies reviewed, those conducted by researchers at CADTH followed organisation-specific protocols to conduct ESs of policy, practice, and research issues, and use of healthcare technologies and provide this evidence to healthcare decision-makers. ${ }^{48}$ Of the non-CADTH studies reviewed, few referenced a specific ES guiding framework or model specific to the implementation of an ES. ${ }^{29} 448299127$ Most frameworks were developed within business or education contexts; two ES studies reported being guided or informed by scoping review methods. ${ }^{123} 153$ Existing models can be helpful to guide the development of a conceptual model or framework for ES. For example, Wilburn et al describes a sevenstep process for conducting an ES in a public health context and maintained the process could be applied to other health issues and research. ${ }^{41}$

Given the paucity of methodological guidance for ESs within the health services delivery context, exploring the development of a guiding framework for conducting an
ES specific to this context could potentially enhance the rigour of these studies and make an important contribution to future research and practice.

Finally, several studies in this scoping review and other studies noted the importance of engaging stakeholders in the ES process. ${ }^{29} 4168153$ This aligns with the current efforts to engage stakeholders in health services delivery decision-making and in health research. ${ }^{167168}$ For example, in a study aimed at improving patient safety in primary care settings by engaging patients and families, stakeholders were involved throughout the ES process including data collection. ${ }^{153}$

\section{Limitations of the scoping review \\ Strengths and limitations}

This scoping review examined a topic not previously examined and followed an established rigorous method for conducting scoping reviews. A data dictionary was developed to promote consistency in data extraction and researchers met regularly to discuss data extraction and the findings. Data were categorised according to the description/terminology as presented by the authors in the individual included studies. The limitations placed on the grey literature may have resulted in some relevant studies being missed. Broad search terms were used to help mitigate this possibility. The included studies were not assessed for methodological quality.

\section{Future research and directions}

The conceptual and methodological gaps identified in this scoping review raise important questions for future research and the advancement of ES within a health services delivery context.

1. Would a consensus definition, consistent terminology and/or a model or framework provide helpful guidance to support researchers and advance the ES as a methodological approach used to support decision making on policy and practice?

2. What types of guidance would a model or framework provide (eg, type of information gathered, environments assessed (internal/external), methods and/or types of sources)?

Our future work will involve a further review of the literature and consultation with experts (eg, researchers, policy-makers, practitioners and other stakeholders) to build on and refine the working definition presented in this paper to potentially establish a consensus definition of an 'ES' within a health services delivery context. We will also explore the development of a conceptual model or framework that may be of assistance to stakeholders who design and conduct ESs.

The findings from this scoping review showed that in $20 \%$ of the studies the evidence generated from the ES was used to help inform policy and practice recommendations on a range of issues. A potential topic for future research could examine how ESs ultimately informed decision-making. 
Finally, the scoping review was purposely focused on the studies that specified use of an "environmental scan' to address a specific health service delivery issue. Further research may examine other analytical methods or techniques that include or are similar to ESs such as situational analysis or the Strengths, Weaknesses, Opportunities, Threats (SWOT) technique that may be used in business and strategic planning.

\section{CONCLUSION}

This scoping review provided insights into the characteristics of ESs and how they are described, conceptualised, designed and implemented as reported in the peer-reviewed and grey health services delivery literature. Significant conceptual and methodological gaps were identified. Consistent terminology and/or definition along with structured methodological guidance could support stakeholders in their attempts to design and implement ESs while contributing to the strength of ES to support policy and programme development. We presented a preliminary working definition as a first step in exploring a conceptual definition in future work.

Health systems operate in a complex, dynamic environment, responding constantly to current or emerging issues and unpredictable events that can impact service quality and efficiency. Evidence gathered through ESs can support decision making and assist healthcare organisations to respond, adapt and build on potential challenges and opportunities.

\section{Author affiliations}

${ }^{1}$ Adjunct Faculty, Faculty of Nursing, University of Prince Edward Island,

Charlottetown, Prince Edward Island, Canada

${ }^{2}$ Faculty of Nursing, University of Prince Edward Island, Charlottetown, Prince

Edward Island, Canada

${ }^{3}$ Women's College Hospital Institute for Health System Solutions and Virtual Care, Dalla Lana School of Public Health, University of Toronto, Toronto, Ontario, Canada ${ }^{4}$ College of Nursing, University of Manitoba Faculty of Health Sciences, Winnipeg, Manitoba, Canada

${ }^{5}$ Psychobiology of Stress and Health Lab, Psychology Department, Mount Allison University, Sackville, New Brunswick, Canada

${ }^{6}$ Department of Nursing and Health Sciences, University of New Brunswick, Saint John, New Brunswick, Canada

${ }^{7}$ Department of Applied Human Sciences, Faculty of Science, University of Prince Edward Island, Charlottetown, Prince Edward Island, Canada

${ }^{8}$ Robertson Library, University of Prince Edward Island, Charlottetown, Prince Edward Island, Canada

${ }^{9}$ Maritime SPOR SUPPORT Unit, Halifax, Nova Scotia, Canada

Acknowledgements We wish to acknowledge and thank Christine Fahim, PhD, Scientist, Li Ka Shing Knowledge Institute, St. Michael's Hospital, Toronto, Ontario, Canada, for reviewing the initial draft of the manuscript and providing helpful feedback.

Contributors All team members contributed to this research including the search strategy, and preparation and editing of the manuscript. LB, a health sciences librarian, developed the search strategy in consultation with the research team. A second health services librarian (KM) conducted a peer review of the initial search strategy developed in the scoping review protocol, translated the search to other databases and provided reproducible electronic search strategies for all database searches. Kate Kelly, a PhD student, assisted with the first level screening. Team members contributed to the screening and analysis of results (PC, TK, RHL, DAN, RA, SD, AL,WJM). PC developed the initial draft of the manuscript, and after several iterations with significant input from the research team, team members (PC, TK, RHL, DAN, RA, SD, AL, WJM) approved the final manuscript submitted for publishing.

Funding The authors have not declared a specific grant for this research from any funding agency in the public, commercial or not-for-profit sectors.

Competing interests None declared.

Patient consent for publication Not applicable.

Provenance and peer review Not commissioned; externally peer reviewed.

Data availability statement All data relevant to the study are included in the article or uploaded as online supplemental information. Most data relevant to this study are included in the article or uploaded as supplemental information. The study protocol and the data dictionary for the data elements in the scoping review are available upon request from the corresponding author.

Supplemental material This content has been supplied by the author(s). It has not been vetted by BMJ Publishing Group Limited (BMJ) and may not have been peer-reviewed. Any opinions or recommendations discussed are solely those of the author(s) and are not endorsed by BMJ. BMJ disclaims all liability and responsibility arising from any reliance placed on the content. Where the content includes any translated material, BMJ does not warrant the accuracy and reliability of the translations (including but not limited to local regulations, clinical guidelines, terminology, drug names and drug dosages), and is not responsible for any error and/or omissions arising from translation and adaptation or otherwise.

Open access This is an open access article distributed in accordance with the Creative Commons Attribution Non Commercial (CC BY-NC 4.0) license, which permits others to distribute, remix, adapt, build upon this work non-commercially, and license their derivative works on different terms, provided the original work is properly cited, appropriate credit is given, any changes made indicated, and the use is non-commercial. See: http://creativecommons.org/licenses/by-nc/4.0/.

\section{ORCID iDs}

Patricia Charlton http://orcid.org/0000-0002-4397-1419

Terri Kean http://orcid.org/0000-0002-0211-3055

Rebecca H Liu http://orcid.org/0000-0002-3946-4035

Daniel A Nagel http://orcid.org/0000-0002-8089-589X

Shelley Doucet http://orcid.org/0000-0003-4420-8199

Alison Luke http://orcid.org/0000-0002-2800-579X

William Montelpare http://orcid.org/0000-0002-4167-4613

\section{REFERENCES}

1 Choo CW. The art of scanning the environment. In: Voros J, ed. Reframing environmental scanning: a reader on the art of scanning the environment. monograph series. Hawthorn, Australia: Australian Foresight Institute, Swinburne University of Technology, 2003: No. 4. 7-18.

2 Choo CW. Environmental scanning as information seeking and organizational learning. Inf Res 2001;7:1-26.

3 Eastough Net al. Improving resilience through environmental scanning in Western Australia. In: Boston J, Wanna J, Lipski V, eds. Future-Proofing the state: managing risks, responding to crisis and building resilience. Canberra, Australia: Australia National University Press, 2014: 135-46.

4 Zhang X, Majid S, Foo S. Environmental scanning practices of travel agent companies in Singapore. Asia Pacific Journal of Tourism Research 2013;18:823-48.

5 Albright K. Environmental scanning: radar for organizational success. Inf Manag J 2004;38:38-45.

6 Hough JR, White MA. Scanning actions and environmental dynamism: gathering information for strategic decision making. Manag Decis 2004;42:781-9.

7 Ahmad Ala'Eddin Mohammad Khalaf, Ahmad AMK. Macroenvironment influences on health service strategy in Saudi private sector hospitals: an empirical investigation. IBR 2012;5:49-64.

8 Tarver WL, Menachemi N. Environmental market factors associated with electronic health record adoption among cancer hospitals. Health Care Manage Rev 2018;43:303-14.

9 Layman EJ, Bamberg R. Environmental scanning and the health care manager. Health Care Manag 2005;24:200-8.

10 Robinson CV, Ahmad F, Simmons JEL. Consolidation and fragmentation in environmental scanning: a review and research agenda. Long Range Plann 2021;54:101997. 
11 Auster E, Choo CW. Environmental scanning by CEOs in two Canadian industries. J Am Soc Inf Sci 1993;44:194-203.

12 Daft RL, Sormunen J, Parks D. Chief executive scanning, environmental characteristics, and company performance: an empirical study. Strateg Manag J 1988;9:123-39.

13 Jogaratnam G. Management style and environmental scanning in the search for business opportunities and challenges. International Journal of Hospitality \& Tourism Administration 2005;6:53-71.

14 Costa J. An empirically-based review of the concept of environmental scanning. Int $J$ Contemp Hospitality Mngt 1995;7:4-9.

15 Fahey L, King WR. Environmental scanning for corporate planning. Bus Horiz 1977;20:61-71.

16 Raymond L, Julien P-A, Ramangalaby C. Technological scanning by small Canadian manufacturers. J Small Bus Man 2001;39:123-38.

17 Jain SC. Environmental scanning in U.S. corporations. Long Range Plann 1984;17:117-28.

18 Pashiardis P. Environmental scanning in educational organizations: uses, approaches, sources and methodologies. Intl Jnl of Educational Mgt 1996;10:5-9.

19 Longest B. Strategic management and public policy. In: Leatt P, Mapa J, eds. Government relations in the health care industry. Westport, Connecticut: Greenwood Publishing Group, 2003: 6. 55-9

20 Tofts A, Walshe K. Managing resources. In: Walshe K, Smith J, eds. Healthcare management. 2nd ed. New York: Open University Press, McGraw-Hill Education, 2011: 452-69.

21 Wright P. Strategic planning: a collaborative process. Nurs Manage 2020;51:40-7.

22 Duncan RB. Characteristics of organizational environments and perceived environmental uncertainty. Adm Sci Q 1972;17:313-27.

23 Morgan PI. The environment. In: La Monica EL, ed. Management in health Care-A theoretical and experiential approach. New York, NY: Palgrave Macmillan, 1994: 461-7.

24 Babalhavaeji F, Farhadpoor MR. Information source characteristics and environmental scanning by academic library managers. Inf Res Int Electron J 2013;18.

25 Brown S. Strategies health care leaders use to implement strategic change initiatives successfully. Walden Diss Dr Stud 2020 https:// scholarworks.waldenu.edu/dissertations/8861

26 Pourmohammadi K, Bastani P, Shojaei P, et al. A comprehensive environmental scanning and strategic analysis of Iranian public hospitals: a prospective approach. BMC Res Notes 2020;13:179.

27 Pulaj E, Pulaj I. The effects of strategic environmental analysis on organizational performance. UBT Int Conf Manag Bus Econ 2015;27:85-92.

28 Graham P, Evitts T, Thomas-MacLean R. Environmental scans: how useful are they for primary care research? Can Fam Physician 2008:54:1022-3.

29 Rowel R, Moore ND, Nowrojee S. The utility of the environmental scan for public health practice: lessons from an urban program to increase cancer screening. J Natl Med Assoc 2005;97:527-34.

30 Nkongolo-Bakenda J-M. Environmental scanning in globally oriented small businesses: practices suggested by managers. $J$ Comp Int Manag 2003;6:23-57.

31 Robinson CV, Simmons JEL. Organising environmental scanning: exploring information source, mode and the impact of firm size. Long Range Plann 2018;51:526-39.

32 Canadian Blood Services. Keeping the promise: strategic plan 2019-2024, 2019. Available: https://www.blood.ca/en [Accessed Feb 2021].

33 Southern Health-Sante Sud. Southern Health-Sante Sud strategic health plan 2016-2021. Available: https://www.southernhealth.ca/ assets/AnnualReports/c2f9a8e99e/Strategic-Health-Plan-2016-21. pdf [Accessed Feb 2021].

34 Ontario Ministry of Health and Long Term Care, Ontario's LHINs. Environmental scan 2019-2022 integrated health service plans, 2018. Available: http://www.wwlhin.on.ca/ /media/sites/ww/files/ goalsandachievements/DATA_06112019_IHSP_EVSCAN_FULL. pdf?la=en [Accessed Feb 2021]

35 Royal College of Physicians and Surgeons of Canada. Cutting through the health system information fog: Royal College environmental scan, 2017. Available: https://www.royalcollege.ca/ rcsite/documents/health-policy/enviromental-scan-e.pdf [Accessed Feb 2021].

36 Ontario Hospital Association. Ontario Hospital association strategic plan 2018-2021. Available: www.oha.com/strategicplan [Accessed Jan 2021].

37 Stacey D, Carley M, Kohli J, et al. Remote symptom support training programs for oncology nurses in Canada: an environmental scan. Can Oncol Nurs J 2014;24:78-82.
38 American Institutes for Research. Environmental scan of patient safety education and training programs. Washington, DC: agency for healthcare research and quality, 2013. Available: https://www. ahrq.gov/research/findings/final-reports/environmental-scanprograms/index.html [Accessed Jan 2021].

39 Ontario Fall Prevention CollaborativeManafò E, . An environmental scan of older adult fall prevention indicators. Toronto, Ontario Ontario Fall Prevention Collaborative, Ontario Neurotrauma Foundation; 2020. https://onf.org/wp-content/uploads/2020/06/ OFPCollaborative-Environmental-Scan-Indicators-April-2020-v9.pdf [Accessed Feb 2021].

40 Valiani S, Rigal R, Stelfox HT, et al. An environmental scan of quality indicators in critical care. CMAJ Open 2017;5:E488-95.

41 Wilburn A, Vanderpool RC, Knight JR. Environmental scanning as a public health tool: Kentucky's human papillomavirus vaccination project. Prev Chronic Dis 2016;13:E109.

42 Marton C. Environmental scan on women's health information resources in Ontario, Canada. Inf Res 2001;7.

43 Scobba V. PS1-23: the environmental scan: a valuable community health research tool. Clin Med Res 2010;8:184-5.

44 Naumann DN, Reynolds JN, McColl MA. Environmental scan of programs for fetal alcohol spectrum disorder in eastern Ontario. $J$ Dev Disabil 2013;19:29-49.

45 Charlton P, Doucet S, Azar R, et al. The use of the environmental scan in health services delivery research: a scoping review protocol. BMJ Open 2019;9:e029805.

46 Zhang X, Majid S, Foo S, et al. Environmental scanning: an application of information literacy skills at the workplace. J Inf Sci 2010;36:719-32.

47 Rathi D, Shiri A, Cockney C. Environmental scan: a methodological framework to initiate digital library development for communities in Canada's North. Aslib Journal of Information Management 2017;69:76-94.

48 Canadian Agency for Drugs and Technologies in Health (CADTH). Environmental scan process; 2015.

49 Arksey H, O'Malley L. Scoping studies: towards a methodological framework. Int J Soc Res Methodol 2005;8:19-32.

50 Peters MDJ, Godfrey CM, Khalil H, et al. Guidance for conducting systematic scoping reviews. Int J Evid Based Healthc 2015;13:141-6.

51 Peters M, Godfrey C, Mclnerney P. Chapter 11: Scoping Reviews. In: Aromataris E, Munn Z, eds. JBI manual for evidence synthesis, 2020. https://wiki.jbi.global/display/MANUAL/Downloadable+PDF++current+version

52 Levac D, Colquhoun H, O'Brien KK. Scoping studies: advancing the methodology. Implement Sci 2010;5:69.

53 Khalil H, Peters M, Godfrey CM, et al. An evidence-based approach to scoping reviews. Worldviews Evid Based Nurs 2016;13:118-23.

54 Tricco AC, Lillie E, Zarin W, et al. A scoping review on the conduct and reporting of scoping reviews. BMC Med Res Methodol 2016;16:15.

55 Aromataris E, Riitano D. Constructing a search strategy and searching for evidence. A guide to the literature search for a systematic review. Am J Nurs 2014;114:49-56.

56 Tricco AC, Lillie E, Zarin W, et al. PRISMA extension for scoping reviews (PRISMA-SCR): checklist and explanation. Ann Intern Med 2018;169:467-73.

57 Sampson M, McGowan J, Cogo E, et al. An evidence-based practice guideline for the peer review of electronic search strategies. J Clin Epidemiol 2009;62:944-52.

58 McGowan J, Sampson M, Salzwedel DM, et al. PRESS Peer Review of Electronic Search Strategies: 2015 Guideline Statement. J Clin Epidemiol 2016;75:40-6.

59 New York Academy of Medicine. Library. New York New York Academy of Medicine; 2021. https://www.nyam.org/library/ [Accessed Feb 2021]

60 Canadian Agency for Drugs and Technologies in Health (CADTH). Grey matters: a practical tool for searching health-related grey literature. Ottawa, Ontario: Canadian agency for drugs and technology, 2019. Available: https://www.cadth.ca/resources/ finding-evidence/grey-matters [Accessed Jan 2021].

61 Moher D, Liberati A, Tetzlaff J, et al. Preferred reporting items for systematic reviews and meta-analyses: the PRISMA statement. PLoS Med 2009;6:e1000097.

62 Daudt HML, van Mossel C, Scott SJ. Enhancing the scoping study methodology: a large, inter-professional team's experience with Arksey and O'Malley's framework. BMC Med Res Methodol 2013;13:48.

63 Vaismoradi M, Turunen H, Bondas T. Content analysis and thematic analysis: implications for conducting a qualitative descriptive study. Nurs Health Sci 2013;15:398-405. 
64 Braun V, Clarke V. Using thematic analysis in psychology. Qual Res Psychol 2006;3:77-101.

65 Shahid S, Beckmann KR, Thompson SC. Supporting cancer control for Indigenous Australians: initiatives and challenges for cancer councils. Aust Health Rev 2008;32:56-65.

66 Abrahamyan L, Wong J, Pham Ba', et al. Structure and characteristics of community-based multidisciplinary wound care teams in Ontario: an environmental scan. Wound Repair Regen 2015;23:22-9.

67 Ahmad N, Simanovski V, Hertz S, et al. Oral chemotherapy practices at Ontario cancer centres. J Oncol Pharm Pract 2015;21:249-57.

68 Baezconde-Garbanati L, Lienemann BA, Robles M, et al. Implementation of HPV vaccination guidelines in a diverse population in Los Angeles: results from an environmental scan of local HPV resources and needs. Vaccine 2017;35:4930-5.

69 Bak K, Gutierrez E, Lockhart E, et al. Use of continuous infusion pumps during radiation treatment. $J$ Oncol Pract 2013;9:107-11.

70 Bakhru RN, Wiebe DJ, McWilliams DJ, et al. An environmental scan for early mobilization practices in U.S. ICUs. Crit Care Med 2015:43:2360-9.

71 Ball GDC, Ambler KA, Chanoine J-P. Pediatric weight management programs in Canada: where, what and how? Int J Pediatr Obes 2011;6:e58-61.

72 Battye KM, McTaggart K. Development of a model for sustainable delivery of outreach allied health services to remote north-west Queensland, Australia. International Journal of Rural and Remote Health, Research, Education, Practice and Policy 2003;3:194.

73 Bednar EM, Walsh MT, Baker E, et al. Creation and implementation of an environmental scan to assess cancer genetics services at three oncology care settings. J Genet Couns 2018;27:1482-96.

74 Brouwers M, Oliver TK, Crawford J, et al. Cancer diagnostic assessment programs: standards for the organization of care in Ontario. Curr Oncol 2009;16:29-41.

75 Carter N, Valaitis R, Feather J, et al. An environmental scan of health and social system navigation services in an urban Canadian community. SAGE Open Nurs 2017;3:237796081668956.

76 Cartmell KB, Young-Pierce J, McGue S, et al. Barriers, facilitators, and potential strategies for increasing HPV vaccination: a statewide assessment to inform action. Papillomavirus Res 2018;5:21-31.

77 Chang F, Paramsothy T, Roche M, et al. Patient, staff, and clinician perspectives on implementing electronic communications in an interdisciplinary rural family health practice. Prim Health Care Res Dev 2017;18:149-60.

78 Davies B, Edwards N, Ploeg J, et al. Insights about the process and impact of implementing nursing guidelines on delivery of care in hospitals and community settings. BMC Health Serv Res 2008;8:29.

79 DeGroff A, Coa K, Morrissey KG, et al. Key considerations in designing a patient navigation program for colorectal cancer screening. Health Promot Pract 2014;15:483-95.

80 Delparte JJ, Chau BA, Mills S, et al. Spinal cord essentials: the development of an individualized, handout-based patient and family education initiative for people with spinal cord injury. Spinal Cord 2014;52:400-6.

81 Finnigan-Fox G, Matlock DD, Tate CE, et al. Hospice, she yelped: examining the quantity and quality of decision support available to patient and families considering hospice. J Pain Symptom Manage 2017:54:916-21.

82 Fong AJ, Jones JM, Faulkner G, et al. Exploring cancer centres for physical activity and sedentary behaviour support for breast cancer survivors. Curr Oncol 2018;25:365-72.

83 Frost JR, Cherry RK, Oyeku SO, et al. Improving sickle cell transitions of care through health information technology. Am J Prev Med 2016;51:S17-23.

84 Glurich I, Nycz G, Acharya A. Status update on translation of integrated primary dental-medical care delivery for management of diabetic patients. Clin Med Res 2017;15:21-32.

85 Goldwater JC, Kwon NJ, Nathanson A, et al. Open source electronic health records and chronic disease management. J Am Med Inform Assoc 2014;21:e50-4.

86 Gustafson DL, Goodyear L, Keough F. When the dragon's awake: a needs assessment of people injecting drugs in a small urban centre. Int J Drug Policy 2008;19:189-94.

87 Hauck Y, Rock D, Jackiewicz T, et al. Healthy babies for mothers with serious mental illness: a case management framework for mental health clinicians. Int J Ment Health Nurs 2008;17:383-91.

88 Hogan TP, Nazi KM, Luger TM, et al. Technology-Assisted patient access to clinical information: an evaluation framework for blue button. JMIR Res Protoc 2014;3:e18.

89 Hogenbirk JC, Brockway PD, Finley J, et al. Framework for Canadian telehealth guidelines: summary of the environmental scan. J Telemed Telecare 2006;12:64-70.
90 Jeon J, White RE, Hunt RG, et al. Optimizing the design of preprinted orders for ambulatory chemotherapy: combining oncology, human factors, and graphic design. J Oncol Pract 2012;8:97-102.

91 Joschko J, Keely E, Grant R, et al. Electronic consultation services worldwide: environmental scan. J Med Internet Res 2018;20:e11112.

92 Kobe CM, Turcotte LM, Sadak KT. A narrative literature review and environmental scan of self-management education programs for adolescent and young adult survivors of childhood cancer. J Canc Educ 2020;35:731-5.

93 Leiva Portocarrero ME, Garvelink MM, Becerra Perez MM, et al. Decision AIDS that support decisions about prenatal testing for Down syndrome: an environmental scan. BMC Med Inform Decis Mak 2015:15:76.

94 Liddy C, Hogel M, Blazkho V, et al. The current state of electronic consultation and electronic referral systems in Canada: an environmental scan. Stud Health Technol Inform 2015;209:75-83.

95 Liddy C, Mill K. An environmental scan of policies in support of chronic disease self-management in Canada. Chronic Dis Inj Can 2014;34:55-63.

96 Luke A, Doucet S, Azar R. Paediatric patient navigation models of care in Canada: an environmental scan. Paediatr Child Health 2018;23:e46-55.

97 Mansell K, Edmunds K, Guirguis L. Pharmacists' scope of practice: supports for Canadians with diabetes. Can J Diabetes 2017;41:558-62.

98 McDonald M, Acri M. Mental health services for maternal depression: a need for system-level change. Soc Work Ment Health 2018:16:630-46.

99 Mew EJ, Ritchie SD, VanderBurgh D, et al. An environmental scan of emergency response systems and services in remote first nations communities in northern Ontario. Int $J$ Circumpolar Health 2017;76:1320208.

100 Mitchell AM, King DK, Kameg B, et al. An environmental scan of the role of nurses in preventing fetal alcohol spectrum disorders. Issues Ment Health Nurs 2018;39:151-8.

101 Moore C, Lee J, Milligan J, et al. Physical activity as medicine among family health teams: an environmental scan of physical activity services in an interdisciplinary primary care setting. Appl Physiol Nutr Metab 2015;40:302-5.

102 Morton G, Walker-Dilks C, Baldassarre F, et al. Delivery of brachytherapy for cervical cancer: organisational and technical advice to facilitate high-quality care. Clin Oncol 2010;22:605-14.

103 Munce SEP, Laan RV, Levy C, et al. Systems analysis of community and health services for acquired brain injury in Ontario, Canada. Brain Inj 2014;28:1042-51.

104 O'Mahony J, Clark N. Immigrant women and mental health care: findings from an environmental scan. Issues Ment Health Nurs 2018;39:1479903:924-34.

105 Ocampo W, Geransar R, Clayden N, et al. Environmental scan of infection prevention and control practices for containment of hospital-acquired infectious disease outbreaks in acute care hospital settings across Canada. Am J Infect Control 2017;45:1116-26.

106 Patel J, Salit IE, Berry MJ, et al. Environmental scan of anal cancer screening practices: worldwide survey results. Cancer Med 2014;3:1052-61.

107 Porterfield DS, Hinnant LW, Kane H. Linkages between clinical practices and community organizations for prevention: a literature review and environmental scan. Am J Public Health 2012;42:S163-71.

108 Poulin P, Chapman K, McGahan L. Preoperative skin antiseptics for preventing surgical site infections: what to do?/Antiseptiques preoperatoires pour la peau afin de prevenir les infections du site operatoire: que faire? Ornac J 2014;32:12-29.

109 Reitmanova S, Gustafson DL. Primary mental health care information and services for St. John's visible minority immigrants: gaps and opportunities. Issues Ment Health Nurs 2009;30:615-23.

110 Richard L, Furler J, Densley K, et al. Equity of access to primary healthcare for vulnerable populations: the impact international online survey of innovations. Int J Equity Health 2016;15:64.

111 Rosa Fortin M-M, Brown C, Ball GDC, et al. Weight management in Canada: an environmental scan of health services for adults with obesity. BMC Health Serv Res 2014;14:69.

112 Scime NV, Burke SM. Environmental scan of breastfeeding resources in Canadian NICUs. J Obstet Gynecol Neonatal Nurs 2018:47:202-13.

113 Silva GS, Farrell S, Shandra E, et al. The status of telestroke in the United States: a survey of currently active stroke telemedicine programs. Stroke 2012;43:2078-85. 
114 Tark A, Agarwal M, Dick AW, et al. Variations in physician orders for life-sustaining treatment program across the nation: environmental scan. J Palliat Med 2019;22:1032-8.

115 Vandenberg T, Coakley N, Nayler J, et al. A framework for the organization and delivery of systemic treatment. Curr Oncol 2009;16:4-15.

116 Whitton A, Warde P, Sharpe M, et al. Organisational standards for the delivery of intensity-modulated radiation therapy in Ontario. Clin Oncol 2009;21:192-203.

117 Wijeysundera HC, Trubiani G, Abrahamyan L, et al. Specialized multi-disciplinary heart failure clinics in Ontario, Canada: an environmental scan. BMC Health Serv Res 2012;12:236.

118 Wittal DM. Bridging the gap from the oncology setting to community care through a cross-Canada environmental scan. Can Oncol Nurs J 2018;28:38-45.

119 Wittich W, Höbler F, Jarry J, et al. Recommendations for successful sensory screening in older adults with dementia in long-term care: qualitative environmental scan of Canadian specialists. BMJ Open 2018;8:e019451.

120 Wolff JL, Kim VS, Mintz S, et al. An environmental scan of shared access to patient portals. J Am Med Inform Assoc 2018;25:408-12.

121 Wurz A, Daeggelmann J, Albinati N, et al. Physical activity programs for children diagnosed with cancer: an international environmental scan. Support Care Cancer 2019;27:1153-62.

122 Yergens D, Fradgley E, Aiyar R, et al. An environmental scan of medical assessment units in Canada. Healthc Q 2014;17:28-33.

123 Archer NP, Fevrier-Thomas U, Lokker C. Electronic personal health records: an environmental scan. Hamilton, Ontario McMaster eBusiness Research Centre, McMaster University; 2010. https:// macsphere.mcmaster.ca/handle/11375/5345 [Accessed Jan 2021].

124 Association of Maternal \& Child Health Programs. Environmental scan: how state title v programs are responding to autism spectrum disorder and other developmental disabilities. Washington, DC Association of Maternal \& Child Health Programs; 2011. http://www. amchp.org/programsandtopics/CYSHCN/resources/Documents/ FINAL 2011\%20Autism\%20Environmental\%20Scan.pdf [Accessed Jan 2021]

125 Bandali F. Breastfeeding guidelines, practices and services in Alberta Health Services-an environmental scan. Edmonton, Alberta Alberta Health Services; 2014. https://www.albertahealthservices. ca/assets/info/hp/hcf/if-hp-hcf-bf-envscan.pdf [Accessed Jan 2021].

126 Bella M, Cobb E, Rothstein J. Health supports for consumers with chronic conditions. Hamilton, New Jersey The Centre for Health Care Strategies, Inc; 2005. http://www.chcs.org/media/ ESMVPFINAL.pdf [Accessed Jan 2021]

127 Blackman N. Chronic Disease and Injury Prevention Programming for Canada's Indigenous Population [dissertation] Walden Dissertation and Doctoral Studies, Walden University; 2018. https:// scholarworks. waldenu.edu/cgi/viewcontent.cgi?article $=6444 \&$ context=dissertations [Accessed Feb 2021].

128 Boonyasai R, ljagbemi O, Pham J. Improving the emergency department discharge process: environmental scan report. Rockville, Maryland Agency for Healthcare Research and Quality; 2014. https://www.ahrq.gov/sites/default/files/ wysiwyg/professionals/systems/hospital/edenvironmentalscan/ edenvironmentalscan.pdf [Accessed Feb 2021]

129 Campos C, Manning L. Improving access project environmental scan report. Winnipeg, Manitoba Brandon Regional Health Authority; 2006. https://ninecircles.ca/wp-content/uploads/2017/04/ Environmental-Scan-Final-Report.pdf [Accessed Feb 2021].

130 Cowling T, Dolcine B. Point-Of-Care testing. Ottawa, Ontario Canadian agency for drugs and technologies in health (CADTH); 2017. https://www.cadth.ca/sites/default/files/pdf/es0308_point_of care_testing.pdf [Accessed Feb 2021].

131 Deshpande A, Khoja S, Lorca J. Asynchronous Telehealth: systematic review of analytic studies and environmental scan of relative initiatives. Ottawa, Ontario Canadian Agency for Drugs and Technologies in Health (CADTH); 2008a. https://www.cadth.ca/ asynchronous-telehealth-systematic-review-analytic-studies-andenvironmental-scan-relevant-0 [Accessed Feb 2021]

132 Deshpande A, Khoja S, McKibbon A. Telehealth for acute stroke management (telestroke): systematic review and environmental scan. Ottawa, Ontario Canadian Agency for Drugs and Technologies in Health (CADTH); 2008b. https://www.cadth.ca/sites/default/files/ pdf/456_Telestroke_to_e.pdf [Accessed Feb 2021].

133 Dietitians of Canada. Dietitians in primary health care: a panCanadian environmental scan, 2018. Available: https://www. dietitians.ca/DietitiansOfCanada/media/Documents/Resources/ 2018-Executive-Summary-Dietitians-in-Primary-Health-Care-APan-Canadian-Environmental-Scan.pdf [Accessed Feb 2021].
134 Forsberg VC, Peters R, Napoles A. Environmental scan and literature review: factors that influence preventive service utilization among children covered by medicaid and CHIP. Baltimore, Maryland The Urban Institute; 2014. https://www.urban.org/sites/ default/files/publication/24716/413236-Factors-that-InfluencePreventive-Service-Utilization-among-Children-Covered-byMedicaid-and-CHIP.pdf [Accessed Feb 2021].

135 Garland S. Health interventions in ambulatory cancer care centres. Ottawa, Ontario Canadian Agency for Drugs and Technologies in Health (CADTH); 2015. https://cadth.ca/health-interventionsambulatory-cancer-care-centres [Accessed Feb 2021]

136 Great Plains Quality Innovation Network. Adverse drug events and medication safety environmental scan overview. Lincoln, NE Great Plains Quality Innovation Network; 2014. https://greatplainsqin.org/ wp-content/uploads/2014/10/ade environmental scan final1.pdf [Accessed Feb 2021]

137 HealthTech Solutions, LLC. Alaska environmental scan: final report State of Alaska Department of Health and Social Services; 2018. http://dhss.alaska.gov/HealthyAlaska/Documents/Initiatives/ Environmental Scan Report.pdf [Accessed Feb 2021].

138 Hochman M, Bourgoin A, Saluja S. Environmental scan of primary care-based efforts to reduce readmissions. Rockville, Maryland Agency for Healthcare Research and Quality; 2019. https://www. ahrq.gov/sites/default/files/wysiwyg/patient-safety/primary-carebased-efforts.pdf [Accessed Feb 2021]

139 Loorand-Stiver L. Falls prevention strategies in adult outpatient or community-based mental health and/or addiction programs: environmental scan. Ottawa, Ontario Canadian Agency for Drugs and Technologies in Health (CADTH); 2012a. https://www.cadth.ca/ sites/default/files/pdf/ES_MH_Fall_Preven_Rev_e.pdf [Accessed Feb 2021].

140 Loorand-Stiver L. Transitioning long-term ventilator-dependent patients out of the intensive care unit - an environmental scan. Ottawa, Ontario; 2012b. https://www.cadth.ca/sites/default/files/ pdf/Chronic_Ventilator-es-33_e.pdf [Accessed Feb 2021].

141 Mason J, Ford C. Feeding and swallowing assessment services for pediatric populations in Canada: service provision, practice models, and assessment tools. Ottawa, Ontario Canadian Agency for Drugs and Technologies in Health (CADTH); 2017. https://www.cadth.ca/ sites/default/files/pdf/ES0306_Feeding_Swallowing_Assessment\% 20Services.pdf [Accessed Feb 2021].

142 McGrath DP, Newton DA, Hartling DL. Advancing the evolution insights into the state of e-mental health services in Canada. Ottawa, Ontario Mental Health Commission of Canada; 2017. https://www.mentalhealthcommission.ca/sites/default/files/201708/eMH\%20Environmental\%20Scan_FINAL\%20EN.pdf [Accessed Feb 2021]

143 Moran GE, Snyder CM, Noftsinger RF. Implementing medicationassisted treatment for opioid use disorder in rural primary care: environmental scan volume 1. Rockville, Maryland Agency for Healthcare Research and Quality (ARHQ); 2017. https:// tbhcoe.matrc.org/wp-content/uploads/2019/12/implementingmedication-assisted-treatment-opioid-disorder-rural-primarycare-environmental-scan-volume-one-2017.pdf?9d4e56\&9d4e56 [Accessed Feb 2021]

144 Morrison A. H1N1 and seasonal influenza vaccine practices across Canadian jurisdictions. Ottawa, Ontario Canadian agency for drugs and technologies in health (CADTH); 2009. https://www.cadth. $\mathrm{ca} /$ sites/default/files/pdf/ES6_H1N1_and_Seasonal_Flu_Vaccine_ Practices e.pdf [Accessed Feb 2021].

145 Morrison A, Dowler J. Newborn screening for disorders and abnormalities in Canada. Ottawa, Ontario Canadian Agency for Drugs and Technologies in Health (CADTH); 2011. https://cadth.ca/ sites/default/files/pdf/Newborn_Screening_es-26_e.pdf [Accessed Feb 2021].

146 Murzin K, Furlotte C. Hiv and aging: a 2013 environmental scan of programs and services in Canada - community report The National Coordinating Committee on HIV and Aging; 2015. http:// realizecanada.org/wp-content/uploads/Community-Report-ENWeb-Ready-Low-Resolution.pdf [Accessed Feb 2021].

147 Ndegwa S. Support services for cardiac rehabilitation in Canada. Ottawa, Ontario Canadian Agency for Drugs and Technologies in Health; 2010. https://www.cadth.ca/support-services-cardiacrehabilitation-canada [Accessed Feb 2021].

148 Ndegwa S. Initiatives for healthy aging in Canada. Ottawa, Ontario Canadian Agency for Drugs and Technologies in Health; 2011. https://www.cadth.ca/initiatives-healthy-aging-canada [Accessed Feb 2021].

149 Ndegwa S, Dolcine B, Frey N. Access to and availability of nonpharmacological treatments for chronic non-cancer pain in Canada: an environmental scan. Ottawa, Ontario Canadian Agency for Drugs 
and Technologies in Health (CADTH); 2018. https://www.cadth.ca/ sites/default/files/pdf/es0313_access-to-non-pharmacologicaltreatment-of-pain.pdf [Accessed Feb 2021].

150 Paccagnan J, Kania-Richmond A, Kelly S. An environmental scan of programs and education tools for the management of osteoarthritis Alberta Health Services; 2017. https://www.albertahealthservices. $\mathrm{ca} /$ assets/about/scn/ahs-scn-bjh-oa-programs-and-educationenviro-scan-report.pdf [Accessed Feb 2021].

151 Seal K, Quay T, Campbell K. Ankyloglossia diagnosis and treatment in Canada: an environmental scan. Ottawa, Ontario Canadian Agency for Drugs and Technologies in Health (CADTH); 2018. https://www.cadth.ca/ankyloglossia-diagnosis-and-treatmentcanada-environmental-scan [Accessed Feb 2021]

152 Smith E. Environmental scan assessing the activities engaged in by health units and community health centres to address access and equity in their program delivery and services. Toronto, Ontario Ontario public health association, access and equity Committee; 2001. https://opha.on.ca/OPHA/media/Resources/Resource\% 20Documents/scan.pdf?ext=.pdf [Accessed Feb 2021].

153 Smith K, Baker K, Medstar Health Research Institute. Guide to improving patient safety in primary care settings by engaging patients and families-environmental scan report. Rockville, Maryland Agency for Healthcare Research and Quality; 2017. https://www.ahrq.gov/sites/default/files/wysiwyg/professionals/ quality-patient-safety/patient-family-engagement/pfeprimarycare/ envscan-report.pdf [Accessed Feb 2021].

154 Topfer L-A, Spry C. Detection and diagnosis of sepsis in rural and remote areas of Canada: an environmental scan. Ottawa, Ontario Canadian Agency for Drugs and Technologies in Health (CADTH); 2019. https://www.cadth.ca/sites/default/files/pdf/es0327-remotesepsis.pdf [Accessed Feb 2021].

155 Tran K, Polisena J, Coyle D. Home telehealth for chronic disease management. Ottawa, Ontario Canadian Agency for Drugs and Technologies in Health (CADTH); 2008. https://www.cadth.ca/sites/ default/files//pdf/H0475_Home_Telehealth_tr_e.pdf [Accessed Feb 2021].

156 Wells C, Dolcine B, Frey N. Programs for the treatment of opioid addiction: an environmental scan. Ottawa, Ontario Canadian Agency for Drugs and Technologies in Health (CADTH); 2019. https://cadth.ca/sites/default/files/es/es0335-programs-fortreatment-opioid-addiction-in-Canada.pdf [Accessed Feb 2021].

157 Young C, Helis E, Williams D. Internet-Delivered cognitive behavioural therapy for major depressive disorder and anxiety disorders: an environmental scan. Ottawa, Ontario Canadian Agency for Drugs and Technologies in Health (CADTH); 2018. https://cadth.ca/sites/default/files/pdf/ES0331_iCBT_for_Major Depression_and_Anxiety.pdf [Accessed Feb 2021].

158 Yurick J, Allatt D. Supportive care framework report Alberta Health Services, Cancer Control Alberta; 2016. https://www.albertahealt hservices.ca/assets/info/hp/cancer/if-hp-cancer-supportive-careframework-report.pdf [Accessed Feb 2021].

159 Blanken RL, Liff A. Facing the future: preparing your association to thrive: emerging trends from the ASAE Foundation's ongoing environmental scan research. Washington, DC: American Society of Association Executives, 1999.

160 Chamberlain-Salaun J, Mills J, Usher K. Terminology used to describe health care teams: an integrative review of the literature. $J$ Multidiscip Healthc 2013;6:65-74.

161 Colquhoun HL, Levac D, O'Brien KK, et al. Scoping reviews: time for clarity in definition, methods, and reporting. J Clin Epidemiol 2014;67:1291-4.

162 Nagendrababu V, Dilokthornsakul P, Jinatongthai P, et al. Glossary for systematic reviews and meta-analyses. Int Endod $J$ 2020;53:232-49.

163 Aguilar FJ. Scanning the business environment. New York: Macmillan, 1967.

164 Daft RL, Weick KE. Toward a model of organizations as interpretation systems. Acad Manage Rev 1984;9:284-95.

165 Hatch TF, Pearson TG. Using environmental scans in educational needs assessment. J Contin Educ Health Prof 1998;18:179-84.

166 Ghoshal S. Environmental scanning in Korean firms: organizational Isomorphism in action. J Int Bus Stud 1988;19:69-86.

167 Bombard Y, Baker GR, Orlando E, et al. Engaging patients to improve quality of care: a systematic review. Implement Sci 2018;13:98

168 Nygaard A, Halvorsrud L, Linnerud S, et al. The James Lind alliance process approach: Scoping review. BMJ Open 2019;9:e027473. 